\title{
Occupational Exposure to Mineral Turpentine and Heavy Fuels: A Possible Risk Factor for Alzheimer's Disease
}

\author{
Rafik Helou Pierre Jaecker \\ Internal Medicine Department, Bertinot Juel Hospital, Chaumont-en-Vexin, France
}

Key Words

Alzheimer's disease $\cdot$ Mineral turpentine $\cdot$ Heavy fuels $\cdot$ Risk factors

\begin{abstract}
Background: The association between solvents and Alzheimer's disease (AD) has been the subject of several studies. Yet, only few studies have examined the various solvents separately, and the controls have rarely been monitored long enough. For these reasons and others, we believe that further studies are required. Objectives: The objective of this study was to identify solvents associated with the clinicoradiological diagnostic of AD or mixed-type dementia (MD). Methods: A retrospective case-control study was performed in 156 patients followed up at the Memory Diagnostic Center of Bertinot Juel Hospital (France). The inclusion criteria were known occupation(s), a Mini-Mental State Examination (MMSE) score $\geq 10$ at the first visit, a neuropsychological evaluation performed and a diagnosis established in our Memory Diagnostic Center. The diagnostics were crossed with 9 solvents belonging to two classes of solvents. Exposure was evaluated using French national job-exposure matrices. $\boldsymbol{R e}$ sults: Certain petroleum-based solvents and fuels (i.e. mineral turpentine, diesel fuel, fuel oil and kerosene) were associated with a diagnosis of AD or MD. This association was still significant after adjustment for age, sex and education (adjusted OR: 6.5; 95\% CI: 2-20). Conclusion: Occupational exposure to mineral turpentine and heavy fuels may be a risk factor for $A D$ and $M D$.


Helou and Jaecker: Occupational Exposure to Mineral Turpentine and Heavy Fuels: A Possible Risk Factor for Alzheimer's Disease

\section{Background}

Upon researching the previous occupations of patients in the geriatric unit of Bertinot Juel Hospital, we addressed the possible role of occupational exposure in the development of Alzheimer's disease (AD). The medical literature is rich on this subject, and many agents, including lead [1, 2], acrylamide [3], electric and electromagnetic fields [4-6], mercury [7], copper [8], nitrosamines [9], arsenic [10] and solvents, have been studied without conclusive results. Concerning the association between solvent exposure and AD risk, several studies have reported negative findings [11-16]. To our knowledge, there was only one large-scale study focusing on AD, by Kukull et al. [17], which reported positive findings.

From an in-depth analysis of the contents of those studies, we determined that the question is far from resolved. The case-control study by Kukull et al. [17] focused on 193 recently diagnosed $\mathrm{AD}$ cases from the University of Washington Alzheimer Disease Patient Registry (ADPR) and 243 randomly selected age- and sex-matched controls. A history of exposure to organic solvents yielded an adjusted odds ratio (OR) for AD of 2.3 [95\% confidence interval (CI): 1.1-4.7]. Among males, the OR increased to 6 (95\% CI: 2.1-17.2). The authors concluded that prior exposure to organic solvents was associated with occurrence of AD.

There have been some biological and methodological criticisms of this study. First, an absence of pathophysiological support for the association has been noted [18]. Most of the known biological effects of solvents are associated with an insult to the integrity of the cell membrane; however, in AD, it is the integrity of synapses that is in question [18]. Second, amyloid deposits and neurofibrillary degeneration have never been observed in the autopsies of patients who died of solvent-induced leukoencephalopathies [18]. Concerning the latter fact, it is possible that encephalopathy appears earlier in life than $A D$, and that these patients have not had sufficient time to grow old enough to develop AD.

Methodological criticism emphasized the large number of nonrespondents and excluded participants [19]. Only $66 \%$ of the original case sample and $45 \%$ of the control sample remained for the final analysis. In principle, Kukull et al. [17] were aware of the uncertainty of an $\mathrm{AD}$ diagnosis in the absence of the gold standard technique (i.e. biopsy samples), and consequently they aimed at minimizing false positives and false negatives. For this reason, their study excluded all individuals diagnosed with 'possible' AD dementia from the case group, and all participants with a Mini-Mental State Examination (MMSE) [20] score $<28 / 30$ from the control group.

In the case-control study by Graves et al. [15], cases were derived from the same sample as in the study by Kukull et al. [17] (i.e. the ADPR), except that only participants who had a spouse were included. The authors did not find an association between the risk of AD and solvent exposure. Nevertheless, the duration of solvent exposure in years was significantly associated with the risk of $\mathrm{AD}$, even after adjustment for age and education. This risk disappeared when the duration was multiplied by the intensity of solvent exposure. These findings are not inconsistent, but they do not account for the situation in which, for example, the duration counts twice as much as the intensity.

Other negative studies also raised concerns such as the choice of controls from among participants with brain tumor, cerebrovascular disease or migraine (e.g. Palmer et al. [14]). In the absence of a cognitive assessment of these controls, how can one be certain that they were not participants with dementia, either subclinical or masked by the main neurological pathology? Moreover, some studies did notmention which solvents were studied or researched (e.g. Shalat et al. [13]). All the aforementioned studies, with the exception of the study by Kukull et al. [17], considered all classes of solvents as a single variable. 
Helou and Jaecker: Occupational Exposure to Mineral Turpentine and Heavy Fuels: A Possible Risk Factor for Alzheimer's Disease

Without a direct relationship to AD, Cherry et al. [21] compared the results of neuropsychological tests among workers who were or were not exposed to solvents at a large construction site. Even after adjustment for education and age, significant differences were found in several tests, including the Buschke test [22]. These differences only disappeared after the control group was redefined. Cherry et al. [21] concluded that solvent exposure was not linked to a decrease in test performance. In a prospective study of 30 workers, White et al. [23] found that solvent exposure may result in a lack of performance in cognitive functions, such as visual memory, in the absence of any clinical manifestation.

\section{Methods}

\section{Objective}

To identify solvents associated with the clinicoradiological diagnostic of AD or mixedtype dementia (MD), we conducted a case-control study that was not limited to a single variable (solvent exposure) but instead assessed several solvents individually.

\section{Study Design}

A retrospective case-control study was performed, aimed at identifying solvents associated with the diagnostic of AD or MD among patients observed in our Memory Diagnostic Center. Positive results were adjusted for age, sex and education. We decided to retain only subjects who had undergone neuropsychological evaluations (NPEs), for two reasons: (1) we followed the European Federation of Neurological Societies (EFNS) recommendations about the relevance of quantitative neuropsychological testing in patients with questionable or very early AD [24], and (2) NPEs may minimize the number of false negatives as controls are more likely to be nondemented if they are diagnosed as such after having undergone an NPE.

\section{Setting}

We examined the medical records of all patients $(n=351)$ whose clinical course was followed in our Memory Diagnostic Center between November 4, 2005, and September 10, 2013. All cases were monitored by the same geriatrician, Dr. C. Zinetti. The Memory Diagnostic Center of Bertinot Juel Hospital is part of a network that includes the Beauvais Hospital, where NPEs and brain imaging were performed, and the Amiens University Hospital, where neurological opinions were requested. All three hospitals are located in the region of Picardie, France.

In addition to clinical and neurological examinations, the consultation service of Dr. Zinetti includes anthropometric measures, an initial battery of neuropsychological tests and scales as well as scoring of a patient's autonomy and thymic disorders. The most commonly used tests and scales are the Instrumental Activities of Daily Living (IADL) scale [25], the MMSE [20], the categorical and lexical verbal fluency tests, the 5-word test with cued recall (5WT) [26], the clock drawing test $[27,28]$, the 5-item version of the Geriatric Depression Scale [29], the Hamilton test [30] and the Montgomery-Åsberg Depression Rating Scale (MADRS) [31]. Dr. Zinetti also describes, in a nonstandardized way, the different language, orientation and behavior disorders, as well as failures of autobiographical memory, working memory and reasoning. In addition to clinical, biological and brain imaging examinations, Dr. Zinetti requests the completion of detailed NPEs whenever they are deemed to be an aid in the diagnosis of $\mathrm{AD}$ or in rehabilitation planning; although a neuropsychologist may or may not suggest one or more hypotheses, the diagnosis is made by the physician. 
A Possible Risk Factor for Alzheimer's Disease

\section{Subjects}

Inclusion Criteria

Patients had to have undergone at least 1 NPE by a neuropsychologist to be included in the study, even if not all tests were completed. Furthermore, the participants' previous occupation(s) had to be entered in their folders, and they had to have an MMSE score $\geq 10$ at the first visit.

Exclusion Criteria

Patients were excluded if monitoring was interrupted before the diagnosis of a cognitive disorder could be provided, or if they were monitored in our center but diagnosed elsewhere. Only 156 patients were retained. Their characteristics were as follows: $75 \pm 10$ years of age; an MMSE score of $24 \pm 5$ at the first visit; $65 \%$ female; $29 \%$ with a family history of dementia; $80 \%$ with a cardiovascular disease or cardiovascular risk factor, and $6 \%$ with a history of head trauma.

Matching

We did not perform matching between cases with and those without dementia for two reasons. First, matching would have necessarily reduced the number of controls, who were monitored in our Memory Diagnostic Center and had received an NPE and often neuroimaging, and thus were most valuable because they were more 'normal' than, for example, controls retrieved at random from an electoral list. Second, we had the intention of treating confounding factors (age and educational level) during the logistic regression analysis.

\section{Variables and Statistics}

Exposure Variables

Solvents were defined by job-exposure matrices which are available on the website of the Institut de veille sanitaire (InVS; French Institute for Public Health Surveillance) [32], a public institution under the tutelage of the French Ministry of Health. The InVS offers two programs with job-exposure matrices: Sumex, which evaluates exposure among the active population, and Matgéné. Although Matgéné processes fewer chemical agents than Sumex, it not only integrates data since 1950 but also considers the evolution of techniques and regulations; thus, it may estimate occupational risks over a lifetime. Matgéné was considered to be more appropriate to the nature of our research. This program also provides numerical estimates in terms of the period, probability, intensity and frequency of exposure to a chemical agent for each workstation. Unfortunately, the size of our study population did not allow us to account for these criteria, and we were limited to the concept of exposed/not exposed.

The solvents were classified by Matgéné into two groups: (1) chlorinated solvents, specifically trichloroethylene, tetrachloroethylene, methylene chloride, chloroform (trichloromethane) and carbon tetrachloride (tetrachloromethane), and (2) petroleum-based solvents and fuels, specifically benzene, gasoline fuel, mineral turpentine, diesel fuel, fuel oil and kerosene. The last 3 products are grouped together in Matgéné.

For the analysis of exposure, occupations were crossed with sectors of activities. For occupations, Matgéné uses two classifications: the International Standard Classification of Occupations 1968 (ISCO 68) and the French classification of socioprofessional categories 1994 (PCS 94; developed by the French National Institute of Statistics and Economic Studies). For activities, two classifications are used: the International Standard Industrial Classification (ISIC 75) and the French classification of activities (NAF 2000).

The InVS recommends the ISCO 68 because it is more detailed. Moreover, it is long-lasting and more suitable to the population being studied than the PCS 94. For example, the occupation of farrier does not exist in the PCS 94. Conversely, occupations such as hospital service 
Helou and Jaecker: Occupational Exposure to Mineral Turpentine and Heavy Fuels:

A Possible Risk Factor for Alzheimer's Disease

agent and early childhood educator do not exist in the ISCO 68, yet they exist in the PCS 94. As a general rule, we have, whenever possible, privileged the ISCO 68. The choice between the NAF 2000 and the ISIC 75 was simpler because Matgéné did not allow a search in the ISIC 75 based on keywords. Passage from one classification to another was performed by using the application Transcodage, and assistance with encoding was provided by the application Caps, both of which are available on the InVS website [32].

Research on exposure may be performed by crossing an occupation with a sector. The most frequent intersection was ISCO $68 \times$ NAF 2000 . When the ISCO 68 was used, $86 \%$ of the occupations had a 5-digit code, reflecting an acceptable degree of precision. For 74, 20 and $4 \%$ of the participants, 1, 2 and 3 occupations were cited, respectively. One participant had followed 4 occupations, and 4 participants had never worked.

The neuropsychological tests studied correspond to those used by neuropsychologists at the Beauvais Hospital. They cover many functions or faculties: the Épreuve de dénomination orale d'images ('Test of Oral Picture Naming'; DO 80) [33, 34] explores language; the Batterie d'évaluation cognitive ('Battery of Cognitive Assessment'; BEC 96) [35] explores several fields including learning, resolution of arithmetical problems, naming, orientation and visuoconstructive activity; the Rey-Osterrieth Complex Figure Test (ROCFT) [36, 37] explores visuoconstructive praxis; the adapted French version of the Grober-Buschke test [38-40] explores episodic memory; the Trail Making Test (TMT), composed of part A (TMT-A) and part B (TMT-B) [41], explores attention capacity and perceptive rapidity (TMT-A) and mental flexibility (TMT-B); corresponding tests assess categorical and lexical verbal fluency [42, 43]; the test of judgment based on the criticism of an absurd story [44] explores reasoning; the similarities subtest of the Wechsler Adult Intelligence Scale-Revised (WAIS-R) [45] explores the capacity of conceptualization, and the Stroop test [46] explores the capacity of inhibition.

\section{Diagnostic Variables: Different Types of Dementia}

The criteria adopted in our Memory Diagnostic Center for the diagnosis of AD were the criteria of the National Institute of Neurological and Communicative Disorders and Stroke and the Alzheimer's Disease and Related Disorders Association (NINCDS-ADRDA) [47]. The diagnosis of vascular dementia was based on the Hachinski Ischemic Score [48]. AD and MD were grouped together in a single variable. The criteria for mild cognitive impairment (MCI) were those of Petersen [49]. The other variables studied were age, sex and education (education was defined as ' 1 ' if the certificate of primary education was obtained, otherwise as ' 0 ').

Confounding Factors: Age and Education

Except in the BEC 96, the standards of numerical neuropsychological testing all are already calibrated according to these factors. Additionally, we adjusted our positive results of an association between solvent exposure and a diagnosis of AD or MD for age, education and sex.

Statistical Analysis

For all statistical data, the results are expressed as OR (with 95\% CI) if $\mathrm{p}<0.05$. Means are presented with their standard deviations $( \pm \mathrm{SD})$. The statistical analysis was performed using Epi Info 7.1.2.0 software from the Centers for Disease Control and Prevention (CDC).

\section{Ethics}

The work was conducted in compliance with the requirements of the site's Institutional Review Board/Human Subjects Research Committee. Formal ethical approval was not needed for this analysis of anonymized, routinely collected data. 
Table 1. Characteristics of patients $(n=156)$

\begin{tabular}{l|l}
\hline \multicolumn{2}{l}{ Dement Geriatr Cogn Disord Extra 2014;4:160-171 } \\
\hline DOI: $10.1159 / 000362382$ & $\begin{array}{l}\text { C 2014 S. Karger AG, Basel } \\
\text { www.karger.com/dee }\end{array}$ \\
\hline
\end{tabular}

Helou and Jaecker: Occupational Exposure to Mineral Turpentine and Heavy Fuels: A Possible Risk Factor for Alzheimer's Disease

$\begin{array}{ll}\text { Age at first visit, years } & 75 \pm 10 \\ \text { Female, \% } & 65 \\ \text { MMSE score at first visit } & 24 \pm 5 \\ \text { Duration of monitoring, months } & 15 \pm 18 \\ \text { Outcome, \% } & \\ \quad \text { Still monitored in 2013 } & 30 \\ \quad \text { End of monitoring } & 25 \\ \quad \text { Lost to monitoring } & 35 \\ \quad \text { Monitored elsewhere or deceased } & 10 \\ \text { MRI, \% } & 57 \\ \text { MRI and/or CT scan, \% } & 79 \\ \text { PET scan (DaTSCAN or HMPAO), \% } & 8 \\ \text { With dementia/without dementia/MCI, n } & 96 / 52 / 8 \\ \text { AD/mixed/VaD/other dementia, n } & 58 / 26 / 8 / 4\end{array}$

Values are means \pm SD unless specified otherwise. VaD $=$ Vascular dementia.

Table 2. Comparison between cases and controls

\begin{tabular}{lllr}
\hline & AD and MD (n=84) & Controls (n=52) & p values \\
\hline Duration of monitoring, months & $20 \pm 19$ & $8 \pm 13$ & $<0.05^{\mathrm{a}}$ \\
Age, years & $79 \pm 7$ & $66 \pm 10$ & $<0.05^{\mathrm{a}}$ \\
Female, \% & 64 & 73 & $0.29^{\mathrm{b}}$ \\
Neuroimaging, \% & 100 & 72 & $<0.05^{\mathrm{b}}$ \\
Repeated NPEs (>1 NPE), \% & 15 & 21 & $0.15^{\mathrm{b}}$ \\
\hline
\end{tabular}

Values are means \pm SD unless specified otherwise.

${ }^{\mathrm{a}}$ t test. ${ }^{\mathrm{b}} \chi^{2}$ test.

\section{Results}

Table 1 shows the characteristics of all patients. The mean MMSE score suggests that the demented subjects may have had mild and moderate dementia. Unfortunately, the association between solvent exposure and vascular dementia ( 8 patients) and other dementias (4 patients) could not be studied because of the small size of each group. In the same way, patients having MCI without conversion in 2013 (8 patients) were excluded from the solvent risk analysis.

Table 2 surveys differences between cases (AD or MD) and controls (nondemented). The difference in the duration of monitoring could be explained by the fact that the cases were receiving medicines such as cholinesterase inhibitors as well as other multidisciplinary care. All cases underwent neuroimaging, while the controls required slightly more NPEs than the cases in order to achieve a diagnosis. There was a significant difference in age between the cases and controls, and this may be a limitation due to the absence of matching.

Table 3 shows the results of the different statistical analyses comparing the performance in the NPEs (normal/pathological) between participants who were exposed to different chlorinated or petroleum-based solvents and participants who were not exposed to these solvents. This table distinctly shows that some petroleum solvents are associated with an impairment of episodic memory as well as with several other cognitive impairments. These results led us 
Table 3. Comparison of NPE performance (normal vs. pathological) between participants who were exposed and those who were not exposed to different petroleum-derived and chlorinated solvents

a Petroleum-derived solvents and fuels

\begin{tabular}{|c|c|c|c|c|c|}
\hline & $\geq 1$ Petrol. solv. & Benzene & Gasoline & MT & DFK \\
\hline DO 80 & $3.4(1.3-8.7)$ & NS & NS & NS & $2.9(1.2-6.8)$ \\
\hline BEC 96 & $2.31 .2-4.8)$ & NS & NS & $2.2(1.1-4.5)$ & NS \\
\hline \multicolumn{6}{|l|}{ ROCFT } \\
\hline Time & NS & NS & NS & NS & NS \\
\hline Type & NS & NS & NS & NS & NS \\
\hline Score & $2.3(1.1-4.9)$ & NS & NS & NS & NS \\
\hline Short-term memory & NS & NS & NS & NS & NS \\
\hline Working memory & $3.8(1.5-9.2)$ & NS & NS & NS & $2.7(1.2-5.8)$ \\
\hline \multicolumn{6}{|l|}{ Grober-Buschke test } \\
\hline IIR & $3.7(1.9-7.4)$ & NS & NS & $2.2(1.2-4.3)$ & $3(1.5-5.7)$ \\
\hline FR & $4.9(2.3-10)$ & NS & NS & $2.7(1.2-5.8)$ & $3.2(1.5-6.7)$ \\
\hline TR & $5.2(2.5-10)$ & NS & NS & $3.1(1.5-6.4)$ & $4.2(2-8.4)$ \\
\hline Intrusions & $3.8(1.8-7.9)$ & NS & NS & $2.9(1.4-6.3)$ & $2.5(1.2-5.2)$ \\
\hline Items recognized & $4.4(2-9.7)$ & NS & NS & $2.2(1.1-4.4)$ & $3.3(1.6-6.7)$ \\
\hline False recognition & $3.1(1.3-7.3)$ & NS & NS & NS & $3.5(1.6-7.8)$ \\
\hline DFR & $4(1.9-8.2)$ & NS & NS & $2.6(1.2-5.5)$ & $2.8(1.4-5.8)$ \\
\hline DTR & $3.9(1.9-7.9)$ & NS & NS & $3(1.5-6.1)$ & $3(1.5-6)$ \\
\hline TMT-A time & $2.6(1.3-5.2)$ & NS & NS & $2.9(1.5-5.7)$ & $2(1-3.9)$ \\
\hline TMT-A error & $2.7(1.1-6.5)$ & NS & NS & $2.5(1.1-5.4)$ & $2.3(1-5.1)$ \\
\hline TMT-B time & $4.9(2.3-10)$ & NS & NS & $3.2(1.5-6.8)$ & $3.2(1.6-6.6)$ \\
\hline TMT-B error & $3.9(1.8-8.1)$ & NS & NS & NS & $3(1.5-6.1)$ \\
\hline Semantic fluency & $3.8(1.8-8.1)$ & NS & NS & NS & $2.6(1.3-5.1)$ \\
\hline Categorical fluency & $5.6(2.7-12)$ & NS & NS & $2.6(1.2-5.4)$ & $3.7(1.8-7.6)$ \\
\hline Judgment & $5.4(2.5-12)$ & NS & NS & $2.7(1.3-5.7)$ & $5(2.3-11)$ \\
\hline Similarities & $5(2.3-11)$ & NS & NS & $2.5(1.2-5.2)$ & $5.7(2.6-12)$ \\
\hline \multicolumn{6}{|l|}{ Stroop test } \\
\hline Reading time & NS & NS & NS & NS & NS \\
\hline Reading error & NS & NS & NS & NS & NS \\
\hline Naming time & $3.3(1.4-8.3)$ & NS & NS & NS & NS \\
\hline Naming error & NS & NS & NS & NS & NS \\
\hline Interference time & $4.5(1.8-12)$ & NS & NS & NS & $3.6(1.4-9)$ \\
\hline Interference error & NS & NS & NS & NS & NS \\
\hline
\end{tabular}

b Chlorinated solvents

\begin{tabular}{|c|c|c|c|c|c|c|}
\hline & $\geq 1$ Chlor. solv. & $\mathrm{C}_{2} \mathrm{HCl}_{3}$ & $\mathrm{C}_{2} \mathrm{Cl}_{4}$ & $\mathrm{CH}_{2} \mathrm{Cl}_{2}$ & $\mathrm{CHCl}_{3}$ & $\mathrm{CCl}_{4}$ \\
\hline DO 80 & NS & NS & NS & NS & NS & NS \\
\hline BEC 96 & NS & NS & $2.5(1-6.3)$ & NS & NS & NS \\
\hline \multicolumn{7}{|l|}{ ROCFT } \\
\hline Time & NS & NS & $2.9(1-8.2)$ & NS & NS & $4.1(1.2-14)$ \\
\hline Type & NS & NS & NS & NS & NS & NS \\
\hline Score & NS & NS & $6.5(1.4-30)$ & NS & NS & NS \\
\hline Short-term memory & NS & NS & NS & NS & NS & NS \\
\hline Working memory & NS & NS & NS & NS & NS & NS \\
\hline \multicolumn{7}{|l|}{ Grober-Buschke test } \\
\hline IIR & NS & NS & NS & NS & NS & NS \\
\hline FR & NS & NS & NS & NS & NS & NS \\
\hline TR & NS & NS & NS & NS & NS & NS \\
\hline Intrusions & NS & NS & NS & NS & NS & NS \\
\hline Items recognized & NS & NS & NS & NS & NS & NS \\
\hline False recognition & NS & NS & NS & NS & NS & NS \\
\hline DFR & NS & NS & NS & NS & NS & NS \\
\hline DTR & NS & NS & NS & NS & NS & NS \\
\hline
\end{tabular}


Table 3 (continued)

\begin{tabular}{|c|c|c|c|c|c|c|}
\hline & $\geq 1$ Chlor. solv. & $\mathrm{C}_{2} \mathrm{HCl}_{3}$ & $\mathrm{C}_{2} \mathrm{Cl}_{4}$ & $\mathrm{CH}_{2} \mathrm{Cl}_{2}$ & $\mathrm{CHCl}_{3}$ & $\mathrm{CCl}_{4}$ \\
\hline TMT-A time & NS & NS & NS & NS & NS & NS \\
\hline TMT-A error & NS & NS & NS & NS & NS & NS \\
\hline TMT-B time & $2.7(1.2-5.8)$ & $2.7(1.2-5.8)$ & $5.4(1.5-18)$ & NS & NS & NS \\
\hline TMT-B error & NS & NS & NS & NS & NS & NS \\
\hline Semantic fluency & NS & NS & NS & NS & NS & NS \\
\hline Categorical fluency & NS & NS & NS & NS & NS & NS \\
\hline Judgment & NS & NS & NS & NS & - & NS \\
\hline Similarities & NS & NS & NS & $3.9(1.1-15)$ & - & NS \\
\hline \multicolumn{7}{|l|}{ Stroop test } \\
\hline Reading time & NS & NS & NS & NS & NS & NS \\
\hline Reading error & NS & NS & NS & NS & - & NS \\
\hline Naming time & NS & NS & NS & NS & NS & NS \\
\hline Naming error & NS & NS & NS & NS & - & NS \\
\hline Interference time & NS & NS & $6.2(1.3-30)$ & NS & NS & $10(1.2-82)$ \\
\hline Interference error & NS & NS & NS & NS & NS & $5(1.1-22)$ \\
\hline
\end{tabular}

Values are OR with $95 \% \mathrm{CI}$ in parentheses. $\mathrm{C}_{2} \mathrm{HCl}_{3}=$ Trichloroethylene; $\mathrm{C}_{2} \mathrm{Cl}_{4}=$ tetrachloroethylene; $\mathrm{CH}_{2} \mathrm{Cl}_{2}=$ methylene chloride; $\mathrm{CHCl}_{3}=$ chloroform; $\mathrm{CCl}_{4}=$ tetrachloromethane; Chlor. solv. = chlorinated solvent; $\mathrm{DFK}=$ diesel oil, fuel oil, kerosene; $\mathrm{DFR}$ = delayed free recall; DTR = delayed total recall; FR = free recall; IIR = initial immediate recall; MT = mineral turpentine; Petrol. solv. = petroleum-based solvent; $\mathrm{TR}=$ total recall (free and cued recalls).

Table 4. Association between diagnosis of AD or MD (performed by a geriatrician after a follow-up that included an NPE) and prior exposure to MDFK, adjusted for age, education and sex, using logistic regression

\begin{tabular}{|c|c|c|c|c|c|c|}
\hline & \multicolumn{2}{|l|}{ Model 1} & \multicolumn{2}{|l|}{ Model 2} & \multicolumn{2}{|l|}{ Model 3} \\
\hline & OR $(95 \% \mathrm{CI})$ & $\mathrm{p}$ value & OR $(95 \% \mathrm{CI})$ & $\mathrm{p}$ value & OR $(95 \% \mathrm{CI})$ & $\mathrm{p}$ value \\
\hline Age & $1.3(1.2-1.4)$ & $<0.05$ & $1.2(1.1-1.3)$ & $<0.05$ & $1.3(1.2-1.4)$ & $<0.05$ \\
\hline MDFK & $5.9(1.9-18)$ & $<0.05$ & $6.5(2-20)$ & $<0.05$ & $8.0(2.8-24)$ & $<0.05$ \\
\hline Education & $0.4(0.1-1.3)$ & 0.13 & $0.4(0.1-1.4)$ & 0.16 & & \\
\hline Sex & $2.0(0.6-6.6)$ & 0.24 & & & & \\
\hline Model likelihood ratio & 93 & & 95 & & 97 & \\
\hline
\end{tabular}

The factors of sex and education are not significant, and their interactions with the main variable are not significant (p values not provided in this table).

to generate a new independent variable encompassing the suspicious solvents, which we termed MDFK (mineral turpentine, diesel fuel, fuel oil, kerosene; which stands for white spirit, gasoil, fioul, kérosène, or WGFK, in French).

Subsequently, we tested the effect of exposure to this new variable on the diagnosis of $\mathrm{AD}$ and MD in the same patients. The association between exposure to MDFK and AD or MD was positive even after adjustment (table 4). The fact that age appeared to be a small risk factor can be explained by its retention as a continuous variable. The OR linked to age represents the increase in risk due to an increase of 1 year of age, all variables being unchanged.

The occupations most commonly found among participants with dementia exposed to MDFK were housemaid (ISC0 68: 552), farmer (ISCO 68: 61220), driver (heavy weight, bus, train; ISCO 68: 98540, 98560), baker (ISCO 68: 77620), couturier (ISC0 68: 77390), mason 
Helou and Jaecker: Occupational Exposure to Mineral Turpentine and Heavy Fuels: A Possible Risk Factor for Alzheimer's Disease

(PCS 94: 2151), industrial worker (textile, metal, plastic, etc.; ISCO 68: 75; NAF 2000: 175A, 171, 264B, 252G, 27, etc.), carpenter (ISC0 68: 95410), shoemaker (ISCO 68: 801), welder (PCS 94: 6223) and steel worker (ISCO 68: 72; NAF 2000: 27).

The occupations most commonly found among participants without dementia not exposed to MDFK were administrative assistant, caregiver, teacher and educator, hairdresser and beautician, trader and seller, cook and administrative executive. The diagnostics of participants without dementia varied greatly - for example, normal cognitive status, anxiety, depression, chronic psychosis, other psychiatric disorders, social problems, sleep apnea syndrome, age-related benign cognitive deficit, benign attention disorders, nonevolutive sequelae of cerebral hypoxia, cerebral tumor and sensory deficits.

Chlorinated solvent exposure was associated with a slowdown of a few psychomotor skills, as evidenced by the time required for some tests. However, these solvents were not associated with any memory impairment, especially episodic memory impairment.

\section{Discussion}

Our study has several particularities: the number of solvents under study, the fact that controls were adequately monitored before allocation to the group without dementia, the choice of binary variables for the analysis of NPE results to avoid the effect of extremes, and the choice of the Matgéné program, which evaluates occupational risks not at a given time but for one's entire life from 1950 onwards.

Our results clearly show that, after adjustment for age, education and sex, specific petroleum-based solvents and fuels (i.e. mineral turpentine, diesel oil, fuel oil and kerosene) are associated with a diagnosis of AD or MD. Those petroleum-based solvents were already suspected during the analysis of the NPE results because they were associated with impairment of episodic memory in all its processes, whereas benzene, gasoline fuel and chlorinated solvents were not. It is worth mentioning that low education did not appear to be a risk factor if it was adjusted for with regard to petroleum solvents.

A cross-sectional study by Berr et al. [50] on retirees aged 55-65 years who worked for a French national gas and electricity company showed an association between exposure to different solvents and performance in two tests: the MMSE and the Digit Symbol Substitution Test (DSST) [51]. Benzene and toluene were included among the solvents studied. It is difficult to compare our results with the results of Berr et al. [50]. Their methodology was satisfactory and the number of participants was significant; however, the patients were younger than in our study and had not received clinicoradiological monitoring for the diagnosis of AD. In addition, it seems surprising that a solvent as widespread as mineral turpentine was not included in their analysis.

Other studies have noted a modification in multiple cognitive functions and psychological test results among workers exposed to mineral turpentine [52-54]. The assumption of a cause and effect implies a long latency period between exposure, which occurs at an active age, and AD, which is strongly linked to aging. However, the results of these studies [52-54] argue in favor of deterioration, most likely at a subclinical level, at an active age. In light of these results, one can assume that this latency period is not a period of normality, and that discrete anomalies exist early in life, although those anomalies must be searched for.

Studies on the irreversible effects of other petroleum-based compounds are extremely rare [55]. In fact, the only reason that we studied fuels was that they were grouped with solvents by the Matgéné program. We are aware of the significance that such results might have because they relate to products that are widely used by professionals and individuals. Although the results of our study need to be confirmed by a cohort study, or at least by addi- 
Helou and Jaecker: Occupational Exposure to Mineral Turpentine and Heavy Fuels: A Possible Risk Factor for Alzheimer's Disease

tional case-control studies, we have decided to publish them for one basic reason: despite being sensitive to matters related to the etiology of $\mathrm{AD}$, public opinion requires considerably more than a single study to be alarmed. Publications on, for example, aluminum and electromagnetic fields are a far cry from having changed the daily behavior of populations. By contrast, not to publish our study, despite the probability that our findings are tangible, would be irresponsible. As to why only specific petroleum-based compounds were associated with the risk of $\mathrm{AD}$ and others were not, we do not have a precise answer. Other studies may, if the risk becomes substantial, clarify this point. For now, while admitting to having neither the knowledge nor the expertise of biochemists, we can point out that the compounds in question (i.e. mineral turpentine, diesel fuel, fuel oil and kerosene) have one thing in common: relatively high temperatures of distillation.

\section{Limitations}

The first limitation to our study is the age difference between the cases and controls. By choosing NPEs as a selection criterion, we reduced the number of controls, and no matching was possible. Studies with large sample sizes allowing matching will be needed to confirm our results.

The second limitation is the fact that the compendium of occupations was based on interviews with participants who already had memory disorders. This compendium was prepared by our geriatrician during the first visit and subsequent NPEs. On both occasions, the presence of a close relative or friend was required; this person could complement or correct a participant's answers. Nevertheless, this approach is no guarantee for obtaining accurate answers. Additional studies, equipped with precise means of verification, are warranted.

Our study was conducted in France, on participants subjected to tests that are ordinarily used by French neuropsychologists and geriatricians and for whom exposure to chemical hazards was assessed by tools put in place by the French health authorities. Thus, our samples are reasonably close to the target population. This aspect is encouraging, but it leaves the uncertainty of a potential 'local' bias covering differences to other countries as far as risk assessment and diagnosis are concerned. The best way for our study to be substantiated would be for equivalent studies to be performed in other countries.

\section{Acknowledgments}

This study would not have been possible without the substantial collaboration of Dr. Corrine Zinetti (geriatrician) and Isabelle Pingliez (neuropsychologist). The efforts of Dr. Delphine Psychoyos and Dr. Kate Edmondson from Write Science Right to edit the manuscript are gratefully acknowledged.

\section{Disclosure Statement}

The authors have no conflict of interest relevant to the content of this study. No funding was used to assist in the preparation of the study. 
Helou and Jaecker: Occupational Exposure to Mineral Turpentine and Heavy Fuels: A Possible Risk Factor for Alzheimer's Disease

\section{References}

1 Zawia NH, Lahiri DK, Cardozo-Pelaez F: Epigenetics, oxidative stress, and Alzheimer disease. Free Radic Biol Med 2009;46:1241-1249.

2 Wright RO, Tsaih SW, Schwartz J, Spiro A 3rd, McDonald K, Weiss ST, Hu H: Lead exposure biomarkers and Mini-Mental Status Exam scores in older men. Epidemiology 2003;14:713-718.

-3 Lopachin RM, Gavin T: Acrylamide-induced nerve terminal damage: relevance to neurotoxic and neurodegenerative mechanisms. J Agric Food Chem 2008;56:5994-6003.

4 Sobel E, Davanipour Z, Sulkava R, Erkinjuntti T, Wikström J, Henderson VW, Buckwalter G: Occupations with exposure to electromagnetic fields: a possible risk factor for Alzheimer's disease. Am J Epidemiol 1995;142: 515-524.

5 García AM, Sisternas A, Hoyos SP: Occupational exposure to extremely low frequency electric and magnetic fields and Alzheimer disease: a meta-analysis. Int J Epidemiol 2008;37:329-340.

6 Davanipour Z, Tseng CC, Lee PJ, Sobel E: A case-control study of occupational magnetic field exposure and Alzheimer's disease: results from the California Alzheimer's Disease Diagnosis and Treatment Centers. BMC Neurol 2007; 7:13.

-7 Mutter J, Naumann J, Sadaghiani C, Schneider R, Walach H: Alzheimer disease: mercury as pathogenetic factor and apolipoprotein E as a moderator. Neuro Endocrinol Lett 2004;25:331-339.

-8 Kowalik-Jankowska T, Ruta-Dolejsz M, Wisniewska K, Lankiewicz L, Kozlowski H: Possible involvement of copper(II) in Alzheimer disease. Environ Health Perspect 2002;110(suppl 5):869-870.

-9 de la Monte SM, Neusner A, Chu J, Lawton M: Epidemiological trends strongly suggest exposures as etiologic agents in the pathogenesis of sporadic Alzheimer's disease, diabetes mellitus, and non-alcoholic steatohepatitis. J Alzheimers Dis 2009;17:519-529.

$\checkmark 10$ Gharibzadeh S, Hoseini SS: Arsenic exposure may be a risk factor for Alzheimer's disease. J Neuropsychiatry Clin Neurosci 2008;20:501.

-11 Heyman A, Wilkinson WE, Stafford JA, Helms MJ, Sigmon AH, Weinberg T: Alzheimer's disease: a study of epidemiological aspects. Ann Neurol 1984;15:335-341.

12 French LR, Schuman LM, Mortimer JA, Hutton JT, Boatman RA, Christians B: A case-control study of dementia of the Alzheimer type. Am J Epidemiol 1985;121:414-421.

13 Shalat SL, Seltzer B, Baker EL Jr: Occupational risk factors and Alzheimer's disease: a case-control study. J Occup Med 1988;30:934-936.

14 Palmer K, Inskip H, Martyn C, Coggon D: Dementia and occupational exposure to organic solvents. Occup Environ Med 1998;55:712-715.

15 Graves AB, Rosner D, Echeverria D, Mortimer JA, Larson EB: Occupational exposures to solvents and aluminium and estimated risk of Alzheimer's disease. Occup Environ Med 1998;55:627-633.

16 O’Flynn RR, Monkman SM, Waldron HA: Organic solvents and presenile dementia: a case referent study using death certificates. Br J Ind Med 1987;44:259-262.

17 Kukull WA, Larson EB, Bowen JD, McCormick WC, Teri L, Pfanschmidt ML, Thompson JD, O’Meara ES, Brenner DE, van Belle G: Solvent exposure as a risk factor for Alzheimer's disease: a case-control study. Am J Epidemiol 1995;141:1059-1071.

18 Bleecker ML: Solvent exposure as a risk factor for Alzheimer's disease: a multiple insult hypothesis. Am J Epidemiol 1995;141:1072-1074.

19 Axelson 0: Possibility that solvent exposure is a risk factor for Alzheimer's disease. Am J Epidemiol 1995;141: 1075-1079.

20 Folstein MF, Folstein SE, McHugh PR: 'Mini-mental state': a practical method for grading the cognitive state of patients for the clinician. J Psychiatr Res 1975;12:189-198.

21 Cherry N, Hutchins H, Pace T, Waldron HA: Neurobehavioural effects of repeated occupational exposure to toluene and paint solvents. Br J Ind Med 1985;42:291-300.

22 Buschke H: Selective reminding for analysis of memory and learning. J Verbal Learning Verbal Behav 1973; 12:543-550.

23 White RF, Proctor SP, Echeverria D, Schweikert J, Feldman RG: Neurobehavioral effects of acute and chronic mixed-solvent exposure in the screen printing industry. Am J Ind Med 1995;28:221-231.

24 Sorbi S, Hort J, Erkinjuntti T, Fladby T, Gainotti G, Gurvit H, Nacmias B, Pasquier F, Popescu BO, Rektorova I, Religa D, Rusina R, Rossor M, Schmidt R, Stefanova E, Warren JD, Scheltens P; EFNS Scientist Panel on Dementia and Cognitive Neurology: EFNS-ENS Guidelines on the diagnosis and management of disorders associated with dementia. Eur J Neurol 2012;19:1159-1179.

25 Lawton MP, Brody ME: Assessment of older people: self-maintaining and instrumental activities of daily living. Gerontologist 1969;9:179-186.

26 Dubois B, Touchon J, Portet F, Ousset PJ, Vellas B, Michel B: 'Les 5 mots': épreuve simple et sensible pour le diagnostic de la maladie d'Alzheimer. Presse Med 2002;31:1696-1699.

27 Montani C, Bouati N, Péllissier C, et al: Cotation et validation du test du cadran de l'horloge en psychométrie chez le sujet âgé. Encephale 1997;23:194-199.

28 Wolf-Klein GP, Silverstone FA, Levy AP, Brod MS: Screening for Alzheimer's disease by clock drawing. J Am Geriatr Soc 1989;37:730-734. 
Hoyl MT, Alessi CA, Harker JO, Josephson KR, Pietruszka FM, Koelfgen M, Mervis JR, Fitten LJ, Rubenstein LZ: Development and testing of a five-item version of the Geriatric Depression Scale. J Am Geriatr Soc 1999;47: 873-878.

30 Hamilton M: A rating scale for depression. J Neurol Neurosurg Psychiatry 1960;23:56-62.

-31 Montgomery SA, Åsberg M: A new depression scale designed to be sensitive to change. Br J Psychiatry 1979; 134:382-389.

32 Institut de veille sanitaire (InVS): Outils d'aide à l'évaluation des Expositions professionnelles (Exp-Pro). 2012. http://exppro.invs.sante.fr/accueil (accessed November 30, 2013).

33 Deloche G, Hannequin D: DO 80: Epreuve de dénomination orale d'images. Paris, Centre de Psychologie Appliquée, 1997.

34 Metz-Lutz MN, Kremin H, Deloche G, Hannequin D, Ferrand I, Perrier D, Quint S, Dordain M, Bunel G, Cardebat D, Larroque C, Lota AM, Pichard B, Blavier A: Standardisation d'un test de dénomination orale: contrôle des effets de l'âge, du sexe et du niveau de scolarité chez les sujets adultes normaux. Rev Neuropsychol 1991;1: 73-95.

35 Signoret JL, Bonvarlet M, Benoit N, Bolgert F, Eustache F, Leger JM: Batterie d'estimation des états démentiels: description et validation; in Leys D, Petit H (eds): La maladie d'Alzheimer et ses limites. Congrès de Psychiatrie et de Neurologie de Langue Française. Paris, Masson, 1988, pp 265-270.

36 Rey A: L'examen psychologique dans les cas d'encéphalopathie traumatique. Arch Psychol 1941;28:286-340.

37 Osterrieth PA: Filetest de copie d'une figure complex: contribution à l'étude de la perception et de la mémoire [The test of copying a complex figure: a contribution to the study of perception and memory]. Arch Psychol 1944;30:286-356.

38 Grober E, Buschke H: Genuine memory deficits in dementia. Dev Neuropsychol 1987;3:13-36.

39 van der Linden M, Coyette F, Poitrenaud J, Kalafat M, Calacis F, Wyns C, Adam S; Membres du GREMEM: L'épreuve de rappel libre/rappel indicé à 16 items (RL/RI-16); in van der Linden M, Adam S, Agniel A, Baisset Mouly C, et al (eds): L'évaluation des troubles de la mémoire: présentation de quatre tests de mémoire épisodique (avec leur étalonnage). Marseille, Solal, 2004, pp 25-48.

40 Tounsi H, Deweer B, Ergis A-M, van der Linden M, Pillon B, Michon A, Dubois B: Sensitivity to semantic cuing: an index of episodic memory dysfunction in early Alzheimer disease. Alzheimer Dis Assoc Disord 1999;13: 38-46.

41 Reitan RM: Validity of the Trail Making Test as an indicator of organic brain damage. Percept Mot Skills 1958; 8:271-276.

42 Cardebat D, Doyon B, Puel M, Goulet P, Joanette Y: Formal and semantic lexical evocation in normal subjects: performance and dynamics of production as a function of sex, age and educational level. Acta Neurol Belg 1990;90:207-217.

-43 Rosser A, Hodges JR: Initial letter and semantic category fluency in Alzheimer's disease, Huntington's disease, and progressive supranuclear palsy. J Neurol Neurosurg Psychiatry 1994;57:1389-1394.

44 Hauw J-J, Dubois B, Verny M, Duyckaerts C: La maladie d'Alzheimer. Paris, John Libbey Eurotext, 1997, p 90.

45 Wechsler D: Wechsler Adult Intelligence Scale - Revised. The Psychological Corporation. New York, Harcourt Brace Jovanovich, 1981.

46 Stroop JR: Studies of interference in serial verbal reactions. J Exp Psychol 1935;18:643-662.

47 McKhann G, Drachman D, Folstein M, Katzman R, Price D, Stadlan EM: Clinical diagnosis of Alzheimer's disease: report of the NINCDS-ADRDA Work Group under the auspices of the Department of Health and Human Services Task Force on Alzheimer's disease. Neurology 1984;34:939-944.

48 Hachinski VC, et al: Multi-infarct dementia: a cause of mental deterioration in the elderly. Lancet 1974;ii: 207-209.

49 Petersen RC: Mild cognitive impairment. N Engl J Med 2011;364:2227-2234.

50 Berr C, Vercambre MN, Bonenfant S, Manoux AS, Zins M, Goldberg M: Occupational exposure to solvents and cognitive performance in the GAZEL cohort: preliminary results. Dement Geriatr Cogn Disord 2010;30:12-19.

51 Lezak MD, Howieson DB, Loring DW: Neuropsychological Assessment. New York, Oxford UP, 2004, pp 368-370.

52 Bazylewicz-Walczak B, Marszal-Wiśniewska M, Siuda A: The psychological effects of chronic exposure to white spirit in rubber industry workers. Pol J Occup Med 1990;3:117-127.

53 Lindström K, Wickström G: Psychological function changes among maintenance house painters exposed to low levels of organic solvent mixtures. Acta Psychiatr Scand 1983;303(suppl):81-91.

54 Gamberale F, Annwall G, Hultengren M: Exposure to white spirit. II. Psychological functions. Scand J Work Environ Health 1975;1:31-39.

55 Valpey R, Sumi SM, Copass MK, Goble GJ: Acute and chronic progressive encephalopathy due to gasoline sniffing. Neurology 1978;28:507-510. 